\title{
On Bridging of the Academic-Practitioner Divide in Business Education: New Opportunities in the New Era
}

\author{
Andrew D. Banasiewicz \\ Professor of Practice and Director of Data Science Programs, Merrimack College, N. Andover, MA, \\ USA \\ Professor of Business Analytics, Cambridge College, Boston, MA, USA \\ banasiewicza@merrimack.edu
}

\begin{abstract}
When described by management practitioners, academic management research is often characterized as unconcerned with practical problems and outright dismissive of practitioners' needs, in addition to being jargon-laden, overly mathematical, theoretical, and self-referential. That unflattering characterization is generally believed to be a product of rigor vs. relevance paradox, which is at the core of the perceived lack of practical utility of theoretical management research. More specifically, it is a reflection of systemic misalignment of (management) practitioners' informational needs, which center on insight uniqueness as a key 'ingredient' of organizations' ability to create and sustain competitive advantage, and the broadly framed goals of theoretical research, which emphasize the search for universal truths in the form of generalizations. However, the now rapidly unfolding Age of Data is creating an opportunity to bridge - and perhaps even close - the persistently unproductive management theoretical research - management practice divide. The opportunity to bridge that gap stems from the growing importance of ongoing organizational learning centered on thoughtful and methodologically sound utilization of organizational data resources, recently framed as learning with data, and rooted in the notion of data analytic literacy. This article discusses how the need to validly and creatively utilize readily available and vast data resources can lead to a closer alignment of management practitioners' informational needs and management researchers' theoretical objectives.
\end{abstract}

Keywords: academic-practice gap; organizational learning; learning with data; data analytic literacy, evidence-based management

\section{Introduction}

Plato, whose name is nearly synonymous with intellectual astuteness, wrote some 2,500 years ago that '...until philosophers are kings, or the kings...have the spirit and power of philosophy, and political greatness and wisdom meet in one...cities will never have rest from their evils' (Butler, 2001). The spirit of those timeless insights continues to ring true in many contemporary contexts, including higher education, and especially managementfocused university education where it takes the form of the academic-practitioner divide (Lilien, 2011; Shepherd and Gruber, 2021). Commonly seen through the prism of the (scientific) rigor vs. (managerial) relevance paradox (Bartunek and Rynes, 2014; Birnik and Billsberry, 2008), which pits the importance scientific soundness against practical usefulness, that tradeoff has long been recognized as a problem without a viable solution. That is because to be scientifically sound, research needs to be framed in highly controlled, limited scope context, but to be practically useful, research contexts need to be as close to real world as possible (Banasiewicz, 2019). Consequently and rather predictably, business management focused academic research is largely shunned by practitioners who tend to see it as practically irrelevant, self-referential, jargon-laden, and unnecessarily abstract and methodologically complex. But even when considered within the confines of scientific merit, theoretical researchers' strong preference for uncovering new insights rather than validating previously reported findings ultimately yields a mishmash of nuanced and contextualized informational tidbits that rarely paint a complete or even a meaningful picture. Perhaps George Bernard Shaw was prophetic in his 1905 play Man and Superman, in which he famously declared that 'those who can, do; those who can't, teach'. Right or wrong, Shaw's sentiment has certainly caught on with practitioners, many of whom are fond of using that quote to sum up their disdain for theoretical management research. In the end, Plato's philosophers continue to theorize, while his kings continue to rule with little-to-no regard for philosophers' theories .

That state of affairs, however, is not universal. There are numerous professional practice domains built on the foundation of academic theoretical research - in fact, the now ubiquitous university-based incubators geared toward transforming scientific research into applied systems, products, and technologies offer highly visible and tangible manifestations of mutually beneficial academic-practitioner collaboration (Banasiewicz, 2019; Dev et al. 2020). And even setting aside such expressly collaboration-minded examples, academic research in, for

Reference this paper: Banasiewicz, A. D., 2021. On Bridging of the Academic-Practitioner Divide in Business Education: New Opportunities in the New Era. The Electronic Journal of Knowledge Management, 20(1), pp. 27-35, available online at www.ejkm.com 
example, life sciences plays an integral part in ongoing efforts to improve the efficacy of medical diagnosis and treatment, as evidenced by pharmaceutical, biomedical and numerous other life science organizations' commitment to sourcing from - and contributing to - academic research efforts (Madani et al, 2020; O'Brien, Kaluzny and Sheps, 2014)). In short, the theory-practice gap is, at its core, a domain specific problem, and it is particularly profound within the confines of business management, but why?

The earlier mentioned rigor vs. relevance paradox (Bartunek and Rynes, 2014; Birnik and Billsberry, 2008) offers some hints: scientifically rigorous business research tends not to produce results that are deemed practically useful; if it did, those results would be willfully consumed by management practitioners, who are always on a lookout for a yet another source of competitive advantage. That is also why professionals in domains rooted in natural (as opposed to social) sciences, such as medicine or engineering, see staying abreast of theoretical research breakthroughs as a critical part of professional competence. In other words, in those fields, theory leads practice. That, however, is generally not the case in business management, where practice tends to lead theory. The core reason for that is that business management is an occupation, not a profession, in the sense that it does not require specific credentials, or even a well-defined basis of knowledge. In principle anyone can become a management practitioner, and in fact countless successful managers have had no formal academic training in management. Not surprisingly, norm-breaking, innovative management strategies or processes tend to first emerge in practice, and then become subjects of theoretical research. But that is not all: Given that goal of theoretical research in general is to delineate universally generalizable forces governing phenomena of interest, such broad generalizations offer little value to highly nuanced, context- and situation-framed business management. So, whereas engineers, pharmacologists or medical practitioners can - and commonly do transform scientific research findings into new technologies, drugs or therapies, business management practitioners rarely do the same with outcomes of academic management research.

While the persistence of the academic-practitioner divide in business is widely recognized as a problem in need of a solution (Banasiewicz, 2019; Lilien, 2011; Shepherd and Gruber, 2021), it is generally not seen as posing direct threat to the future of university-based management education Yet, at the time when many question the value of university education in general, such glaring disconnect academic and applied sides of business management further weakens the argument for indispensability of institutions of higher learning to societal progress and well-being. If what collegiate schools of management provide is non-essential to practice of management, what is the value - for individual students and the society at large - of continuing to support those institutions? Thus far business schools are yet to provide a compelling response to that difficult question, but the massive digital transformation that is currently underway offers an opportunity to do so in an empathetic way.

The goal of this paper is to delineate and discuss the key digital transformation related trends and developments from the perspective of bridging of the academic-practitioner divide. More specifically, it is to expressly address the opportunity to more closely align teaching of business management with its practice, by leveraging the growing centrality of data.

\section{The Opportunity is Knocking}

One of the many changes ushered in by the unfolding Age of Data is a steady drift away from largely subjective judgment and experience-emphasizing organizational decision-making, and toward predominantly objective, data-driven model (Banasiewicz, 2019). That is not to say that human reason is being replaced by algorithmic rules - rather, it is the essence of reasoning that is changing, as captured in the now-popular (and widely attributed to W. Edwards Deming, a leading management thinker in the field of quality) quote: 'In Good we trust, all others bring data.' It is that persistently ever more central role that data play in organizational management that is at the core of the emerging opportunity to better align the whats and the hows of business management teaching with the demands of business marketplace.

As attested to by the rapid proliferation of data science and business analytics degree offerings, universities appear to be keenly aware of the importance of meeting the emerging educational needs of the broadly defined learner marketplace - however, the aspect of the current info-technological transformation they seem to overlook is the need to reshape and retool their largely Industrial Era curricula. In other words, institutions of higher learning tend to be more inclined to see the current information technology-led changes as an opportunity to add new programs, and less as a call to fundamentally rethink what and how they teach. Within the confines of management education, adding a degree in, for instance, business analytics all while keeping the 
general curricular logic and structure of the existing business administration programs largely unchanged implicitly assumes that the base curriculum correctly captures current needs of their students, and also that only some graduates need to be analytically literate (as only some will pursue a degree in business analytics). Both of those perspectives are myopic. When personal computers began to emerge as an everyday business tool in the 1980s it was not just some of management schools' graduates who needed to be computer literate similarly, the ubiquity of data now suggests that basic data literacy should be considered a common, elementary competency exhibited by all management graduates, rather than an elective skillset. Meeting that challenge is at the nexus of the opportunity to not just bridge, but perhaps even altogether eliminate the theoreticianpractitioner divide in business education.

What curricular changes should be considered to better align management education with the practice of management? It is a loaded question, and while there are numerous important considerations that need to be addressed, the ensuing discussion is focused on two notionally distinct but epistemically closely related curricular considerations: 1 . expressly differentiating between what it means to manage 'to' and manage 'by' the numbers, and 2. expressly acknowledging (through instructional content and methods) the centrality of robust data analytic literacy.

\section{The Genesis of Organizational Management and the Rising Importance of Data}

The practice of management, commonly framed as a general process of controlling things or people, is inherent to organized living, simply because the very functioning of human collectives requires controlled and organized efforts (George, 1968; McLarney, 1974; Witzel, 2012). Not surprisingly, the earliest evidence of somewhat formalized management practices dates back more than six millennia, to around $4500 \mathrm{BCE}$, and the record keeping developed by early Sumerians; however, it was a Babylonian king, Hammurabi, who oversaw the development of more systemic and formally codified control practices about 2,500 years later. Still, it was the work of a Greek philosopher Xenophon (a student of Socrates), titled Household Management, that is commonly credited with giving rise to management as a separate domain of study and practice (Blok, 2019).

Centuries later, the gradual emergence of modern commercial organizations brought with it a need for more formal tracking of organizational resources and commercial transactions, which in turn contributed another key set of foundational elements to the ongoing maturation of the art and science of managing. In 1494, a Franciscan monk and a noted mathematician Luca Pacioli (he counted Leonardo da Vinci among his students) published a textbook titled Summary of Arithmetic, Geometry, Proportions and Proportionality. While the work was notable as an elegant summary of the collected knowledge of mathematics of the time, its true claim to fame was the now celebrated 26-page guide for merchants on sound accounting and business practices, built around Pacioli's own codification of the Venetian accounting method. Separately titled Details of Calculation and Recording, that guide was the first published detailing of the double entry bookkeeping system, which rapidly spread throughout Europe and beyond, so much so that Pacioli is now considered to be the father or modern accounting ${ }^{1}$ (Parker, 2019).

While those early contributions framed the practice of management in terms of general keeping track and oversight considerations, the process orientation of modern management practice can be seen as a result of the far more recent and more applied work of Frederick Taylor, an American mechanical engineer (Del Mar and Collons, 1976; Witzel, 2012). Taylor is widely acknowledged to be the first to approach managing of work through systematic observation and study; in his seminal work published in 1911 and titled The Principles of Scientific Management, he summarized his theory of effective job and incentive compensation design as a mean of achieving higher productivity. His ideas were widely adopted and, together with other contributions, most notably those by Frank and Lillian Gilbreth (a husband-and-wife duo of industrial engineers), gave rise to what it now known as scientific management, which can be characterized as controlling by means of analysis and synthesis of workflows (Chen and Hitt, 2021). It is worth noting that Taylor's primary focus was on time, thus his studies came to be known as 'time studies'; Gilbreths, on the other hand, were focused on identifying the most efficient ways of accomplishing tasks, thus their research came to be known as 'motion studies.' What is today

\footnotetext{
${ }^{1}$ Today, the idea of separating entity's resources from claims on those resources is known as balance sheet; in a broader sense, Pacioli's work laid the foundation for modern financial statements, which offer a concise way of systematically capturing the key financial aspects of business entities, and by doing so provide objective and unambiguous management targets.
} 
known as 'time-and-motion' studies, and sometimes erroneously entirely attributed to Taylor, represents a subsequent merging (by others) of the two distinct areas of research. More importantly, time-and-motion studies gave rise to fact-based, quantitative facet of management practice (Frederick, 1963; Witzel, 2012).

While the rise of scientific management amplified the idea of using objective, numeric evidence as the basis of organizational decision-making, the general idea of managing 'by the numbers' actually predates the emergence of scientific management (Bangs, 1992; Meek, Woodworth and Dyer, 1988). Beginning in the late 1800s, business organizations began to voluntarily ${ }^{2}$ publish their financials in the form of balance sheet, income statement, and cash flow statements as a way of attracting investors, who used those documents as proof of companies' profit-making abilities (Daniels, 1980). Today, using a business organization's financials as targets is nearly synonymous with the idea of 'managing by the numbers', as illustrated by popular publications such as Managing by the Numbers: A Commonsense Guide to Understanding and Using Your Company's Financials (Kremer, Rizzuto and Case, 2000).

Whether 'the numbers' take the form of financial statements or the earlier outlined operational efficiency metrics, there is little doubt that they represent outcomes of organizational decisions, which raises the question of logical consistency: Is managing organizations by setting explicit performance targets tantamount to truly managing 'by' the numbers, whether those numbers represent production efficiency or aggregate financial results?

\section{To or By the Numbers?}

Notionally, managing 'by' the numbers could be could be likened to piloting a plane in a mode known as 'fly-bywire', which replaces conventional manual flight controls of an aircraft with an electronic interface. In that mode, automated flight control systems use computers to process flight control inputs and send corresponding electrical signals to actuators that control the key functions such as speed, direction, and altitude; stated differently, when operated in fly-by-wire mode, aircrafts' flight path is determined by data. Similarly, objective evidence-guided organizations' decisions are also shaped by data, which reduces organizations' dependance on the often-biased human judgment. In an abstract sense, organizational management could, under those circumstances, be reduced to a simple stimulus-response model where the relationship $(f)$ between the stimulus $(X)$ and the expected $(E)$ outcome $(Y)$ is expressed as a simple function of $E(Y)=f(X)$ (Bugmann Goslin and Duchamp-Viret, 2013; Islam et al., 2018). Is that what happens when organizations are managed by the numbers? The short answer is no.

In a very general sense, organizational management entails choosing among explicit or implied strategic and tactical alternatives under conditions of uncertainty (Jensen, 2002; Marques, 2019); given that, managing by the numbers implies reliance on objective evidence when making those choices. Operationally, that calls for objectively estimating the relative advantage of each of the available decision alternatives, and then choosing the one with the highest expected value (Mann, 2018). All considered, managing by the numbers demands the use of input, not just outcome 'numbers', which calls into question the appropriateness of characterizing the process of aiming to reach specific goals, typically encapsulated in financial performance or operational efficiency targets, via unspecified or unclear means as managing by the numbers.

In March of 2019, Boeing 737 Max, a variant of the company's best-selling Boeing 737 aircraft (itself the bestselling plane in commercial aviation history) was grounded worldwide after 346 people died in two separate crashes. While the underlying fact pattern that led up to those tragedies and the subsequent grounding is complex, some of the more striking aspects of that case include evidence that the company historically renowned for its meticulous designs made seemingly basic software design mistakes, now believed to have played the key role in those crashes. According to longtime Boeing engineers, what should have been a routine development project was complicated by the company's push to outsource that work to lower-paid contractors, some being paid as low as $\$ 9 /$ hour; moreover, as reported by the New York Times, the company's decision to sell as 'extra' certain safety features, most notably those known as 'angle of attack indicators', may have also played a role (Tabuchi and Gelles, 2019).

\footnotetext{
${ }^{2}$ Following the passage of securities acts in the early 1930s that practice became mandatory for companies with publicly traded securities.
} 
An eerily similar example of profit over safety is offered by the Pacific Gas \& Electric Company, commonly known as PG\&E, a California public utility. As reported by the Wall Street Journal (Blunt and Gold, 2019), the company knew for years that hundreds of miles of its electric power lines, some nearly 100 years old, needed to be upgraded to reduce the chance of sparking a fire, but the company's bottom line focus kept it from making the required investments. In 2018 the nightmare scenario came true: a felled power line sparked what eventually became the deadliest wildfire in California's history, claiming 88 lives, causing more than $\$ 30$ billion in potential legal claims, all of which ultimately pushing PG\&E to file for bankruptcy protection. (It is worth noting that while the 2018 wildfire is notable as being the largest, the company's power lines are believed to have caused more than 1,500 wildfires in the span of just 6 years.)

While the cases of Boeing and PG\&G are just two, fairly extreme examples, they are nonetheless illustrative of the fundamental difference between managing to and managing by the numbers. Both Boeing's and PG\&E'S decisions were clearly shaped by financial considerations - clearly, both companies were managing to their respective financial targets. And though managing 'by' the numbers is a widely used label to describe any management approach built around quantitative measures, trying to hit predetermined operational or financial targets is more fittingly characterized as managing 'to' the numbers. It might be tempting to dismiss that distinction as mere semantics, but it is significantly more than that: Managing to the numbers entails orienting decisions toward the attainment of express goals, such as the attainment of specific profitability or operational goals, whereas managing by the numbers calls for reliance on objective evidence as the basis of decision-making. It is the difference between doing whatever is deemed necessary to reach a stated target, and allowing objective evidence to map out the path going forward. While the former entails using judgment as the mean of reaching predetermined performance targets, the latter entails using objective evidence as the means of setting and reaching performance targets. Or stated differently, managing to the numbers effectively subsumes 'how' under 'what', whereas managing by the numbers uses evidence emerging from 'how' to set expectations regarding 'what'. All considered, managing by the numbers can be seen as a manifestation of evidence-based decisionmaking (Banasiewicz, 2019; McCann, 2020), whereas managing to the numbers is ultimately rooted in unempirical, instinctive judgment-based decision-making. That is a critical distinction that simply has to be made clear in management curricula built around data-centric, evidence-based decision-making.

\section{Data Analytic Literacy}

Implied in the practice of managing by the numbers is the idea of data analytic literacy, which is the second key contributor to closing of the academic-practitioner gap. Within the confines of data-driven organizational management, data analytic literacy can be seen as the actuating mechanism of that progressive management philosophy - in other words, it is central to the practice of management and it ought to play central role in teaching of management.

In its simplest definitional form, data analytic literacy can be conceptualized as the ability to extract informative insights out of raw data (Banasiewicz, 2021). It is a summary construct which encompasses elements of analytic reasoning, familiarity with data types and data analytic methodologies, and knowledge of computational tools. Analytic reasoning can be summarized as the clarity of informational purpose, or the 'know-why' dimension of data analytic literacy. While definitionally (and even more so, practically) elusive, the analytic reasoning dimension is critically important, especially in data-rich organizational contexts where overabundance of data can give rise to endless arrays of data analytic outcomes generated not because those outcomes address specific informational needs, but because data and data analytic means are both readily available (Banasiewicz, 2021; Luoma and Martela, 2021; Weinhardt et al., 2015). Stated differently, analytic reasoning is a manifestation of informational discipline, which amounts to staying focused on analytic outcomes that address stated informational needs; it is where the idea that 'less is more' is particularly appropriate.

The remaining two dimensions - familiarity with data types and data analytic methodologies, and knowledge of computational means - can be thought of as the methodological 'know-what' and computational 'know-how', respectively, and comprise what is commonly seen as the core data analytic skillset (Banasiewicz, 2021). The former encompasses a diverse body of knowledge encompassing understanding of data structures, data due diligence and data feature engineering, and familiarity with statistical and/or machine learning approaches to data analysis, while the latter manifests itself in knowledge of appropriate programming languages, such as $R$ or Python, or applications, such as SAS or SPSS. 
While each of the three facets of data analytic literacy can be thought of a distinct domain of knowledge or a set of competencies, together they function as a self-contained system. Each part interacts with, and in fact needs the other parts - it is not possible to engage in productive applied analyses of data without adequate command of the 'why', 'what', and 'how' facets. Stated differently, the ability to extract decision-guiding insights out of data calls for a combination of sound data analytic logic, familiarity with statistical techniques and/or machine learning algorithms, and computational programming skills (Banasiewicz, 2021).

Critical to appreciating the importance of data analytic literacy is the role that broadly defined competency plays in the evolving conception of creative business (and other) problem solving. The currently underway $4^{\text {th }}$ Industrial Revolution is ushering-in the era of expansive work automation, which is laying the foundation for the new age of information-driven creativity (French et al., 2021; Krishnannair and Krishnannair, 2021). Rapid proliferation of 'smart', meaning artificial intelligence-powered technologies is slowly but fundamentally reshaping the nature of work by freeing human time-effort while also producing vast quantities of data, a massive transformation that is creating new human time-effort deployment opportunities. It is important to note that the broadly defined mechanization is not limited to manufacturing - automated and even autonomous systems are fully responsible for a growing array of financial transactions, insurance claims, and other organizational functions traditionally handled by human decision-makers (French et al., 2021; Huynh, Hille and Nasir, 2020). And yet the core aspects of management education are still framed in the now all-but-gone Industrial Era - more specifically, management curricula continue to emphasize assimilation of existing knowledge, even in overtly creative problem-solving contexts ${ }^{3}$. That paradigm needs to change - to meet new challenges created, primarily, by scientific and technological advances, the focus of business education needs to shift more toward competency-enabled creative exploration, in a way that goes beyond looking for old truths in new realities while at the same time retaining enduring truths (i.e., patterns and relationships that persist over time). More on point, business schools' curricula need to thoughtfully combine acquisition of enduring truths, in the form of 'tried and true' elements of managerial knowledge, with learning how to derive completely new insights by creatively yet soundly exploring the vast data riches available nowadays to virtually all organizations. It is in that context that data analytic literacy emerges as a competency of paramount importance, a mean of heightening data-enabled creative thinking potentiality of today's management learners and future management practitioners.

While its importance is paramount, building broad based data analytic literacy in organizations is fraught with difficulties, most notably because even the most basic analyses of data are unavoidably technical (Frias and Popovich, 2020; Kuzmina et al., 2020). That is not only because analysis of data commonly entails the use of statistical concepts and methods, but also because most raw data require at least some degree of pre-processing to address common deficiencies such as missing or outlying values; quite often, the extent of what is commonly known as 'data wrangling' can be considerable, especially when data also need to be restructured, recoded, aggregated, and amalgamated (Banasiewicz, 2019). Those data analytic competency related challenges represent an opportunity for systematic bridging of the academic-practitioner gap by developing curricular collaborations rooted in the idea of practitioners-identified skills and competencies informing learning outcomes of management curricula. To be truly evidence-based, organizational management needs the foundation of broad base data analytic competency which can - and should - be the core element of management education.

\section{Final Thoughts on Bridging of the Academic-Practitioner Divide}

It is well-known that the core objective of business management is to develop and sustain competitive advantage (Schultz and Flanigan, 2016; Sanchez and Heene, 2010). In view of that, practitioners' general lack of interest in theoretical management research suggests that those efforts are not viewed as helpful in reaching that goal. Why is that the case? What may be seen at times as academic researchers' lack of concern for informational needs of management practitioners, might in fact be a manifestation of a systemic misalignment between goals of researchers and practitioners.

Broadly characterized, scientific inquiry is tantamount to search for universal truths, which means that the essence of theoretical research is to produce informational outcomes that describe generalizable patterns and

\footnotetext{
${ }^{3}$ Perhaps the most common manifestation of that trend are the ubiquitous case studies in which 'discovery' learning tends to boil down to finding of largely pre-arranged patterns, which can ultimately be seen as an alternative mechanism of conveying existing knowledge.
} 
relationships. In contrast to that, attainment (and sustainment) of competitive advantage - by business firms and other organizations - is rooted in informational specificity, not universal generalizations (Holton and Morison, 1979). It thus follows that universal truths-minded outcomes of theoretical management research are not likely to offer the type of insights sought by organizational decision-makers. For instance, a research stream that aims to derive generalizable relationships between certain product attributes and consumer demand will likely be of little interest to brand managers looking for uniquely advantageous mixes of product attributes.

However, the rise of the Age of Data coupled with pervasively disruptive character of rapid info-technological innovation are beginning to radically redefine the character of (management related) theory-practice interactions. More specifically, it amplifies the importance of ongoing organizational learning, centered on thoughtful and methodologically sound utilization of organizational data resources (Banasiewicz, 2021); ; an idea that might sound conceptually straightforward, but usually turns out to be operationally quite complex. Looking beyond the often-raised volume, variety, velocity, and veracity considerations (Business World, 2018), extracting valid and reliable insights from data almost always requires careful separation of informative 'signal' from noninformative 'noise' (Tolin, 2014), in addition to often extensive data wrangling and feature engineering efforts, all capped with well-informed data analytic approach, technique, and tool selection (Banasiewicz, 2019). In short, practice-focused learning with data is, at its operational core, inescapably academic, simply because the goal of extracting competitively advantageous insights out of vast and 'dirty' (i.e., requiring substantial amounts of pre-processing) data calls for deep understanding of know-why and know-how. In that context, theoretical research can make ongoing contribution to strategies, techniques, and tools that are critical to practitioners extracting unique insights out of available data. Yet, that is not all...

\section{Transcendent Creativity}

An even more compelling academic-practitioner divided bridging opportunity stems from the idea of dataenabled creativity, and its higher-order manifestation, transcendent creativity (Banasiewicz, 2021). Both notions are rooted in a fundamental re-definition of the general conception of creativity, traditionally (and somewhat vaguely) framed as the use of imagination to form new ideas, not already present to or in the senses (Roberto, 2019; Sternberg, Grigorenko and Singer, 2004). The notions of data-enabled creativity and transcendent creativity are both rooted in a fundamental question: Is creativity really tantamount to conjuring up something completely otherworldly, in the sense of not having been experienced, or is it creating a new whole - be it an abstract idea or a work of art - by combining already known elements? And if the latter conception sounds reasonable, does it not seem plausible that immersion in data contained 'reality', as in patterns and relationships hidden in raw data, could spark ideas that might not otherwise arise? That line of reasoning captures the essence of data-enabled and, ultimately, transcendent creativity, which in turn suggest an even more fundamental opportunity for linking academic research and managerial practice.

Implied in that more expansive conception of creativity is the organic vs. techno duality, which is a manifestation of the fundamental difference between creativity fueled by individual human experience and reasoning, and creativity made possible by a combination of vast and diverse arrays of data and the rapidly advancing computational technologies, ultimately manifesting itself in advanced computer-rendered simulations. It is the latter of the two contexts that presents a yet another profound opportunity to bridge the academic-practitioner divide: Being able to tap into that practically unlimited informational potential offers incentives for know-howseeking practitioners to work more closely with know-how-commanding academicians; in fact, it may even redirect at least some of the academic management research away from the search for generalizations and toward situationally emerging knowledge.

\section{References}

Banasiewicz, A.D., 2019. Evidence-based decision-making: How to leverage available data and avoid cognitive biases. New York : Routledge, Taylor \& Francis Group

Banasiewicz, A.D., 2021. Organizational learning in the Age of Data.Cham: Springer.

Bangs, D.H,. 1992. Managing by the numbers: financial essentials for the growing business. Dover: Upstart Publishing Co.

Bartunek, J.M., and Rynes, S.L., 2014. Academics and practitioners are alike and unlike: the paradoxes of academicpractitioner relationships. Journal of Management, 40(5), pp. 1181-1201.

Bhatt, N., and Thakkar, A,. 2021. An efficient approach for low latency processing in stream data. Computer Science, 7, p. e426.

Bily, C.A, 2011. Standardized Testing. Detroit, Mich: Greenhaven Press. 
Birnik, A. and Billsberry, J.,(2008. Reorienting the business school agenda: the case for relevance, rigor, and righteousness. Journal of Business Ethics, 82(4),pp. 985-999.

Blok, V.. 2019. Xenophon's philosophy of management. Available at: http://search.ebscohost.com.proxy3.noblenet.org/login.aspx?direct=true\&db=edsair\&AN=edsair.narcis.........5497f82 b576cd688cdcba062c63ecf21\&site=eds-live\&scope=site [Accessed 25 March 2021.

Blunt K. and Gold R., 201). PG\&E knew for years its lines could spark wildfires, and didn't fix them.. Available at: https://www.wsj.com/articles/pg-e-knew-for-years-its-lines-could-spark-wildfires-and-l-fix-them-11562768885 [Accessed22 March 2021]

Bugmann, G. Goslin, J. and Duchamp-Viret, P., 2013. Speed of learning instructed stimulus-response association rules in humans: experimental data and model. Brain Research, 1536,pp. 2-15.

Business World, 2018. Big four vs of big data. April 30. Business World.

Butler, J., 2001. Saving the city: philosopher-kings and other classical paradigms. Ancient Philosophy, 21(1), pp. 246-249.

Chen, V.Z., and Hitt, M.A., 2021. knowledge synthesis for scientific management: practical integration for complexity versus scientific fragmentation for simplicity. Journal of Management Inquiry, 30(2),pp. 177-192.

Daniels, M.B., 1980. Corporation Financial Statements. New York: Arno Press.

Del Mar, D. and Collons, R.D., 1976. Classics in scientific management: a book of readings. Tiscaloosa, Alabama: University of Alabama Press.

Dev, M. D.B., Rusli, K.D.B., McKenna, L., Lau, S.T., and Liaw, S.Y., 2020. Academic-Practice Collaboration in Clinical Education: A Qualitative Study of Academic Educator and Clinical Preceptor Views. Nursing and Health Sciences, 22(4), pp. 1131-1138

Frederick, W.C., 1963. The next development in management science: a general theory. Academy of Management Journal, 6(3), pp. 212-219.

French, A.M., Shim, J.P., Larsen, K.R., Risius, M., and Jain, H.,, 2021. The $4^{\text {th }}$ Industrial Revolution powered by the integration of Al, blockchain, and 5G. Communications of the Association for Information Systems, 49, pp. 266-286.

Frias, K. M., and Popovich, D., 2020. an experiential approach to teaching mixed methods research. Journal of Education for Business, 95(3), pp. 193-205.

George, C.S., 1968. The History of Management Thought. Englewood Cliffs, NJ: Prentice-Hall.

Holton, G.J., and Morison, R.S., 1979. Limits of scientific inquiry. New York: Norton.

Huynh, T.L.D., Hille, E., and Nasir, M.A., 2020. Diversification in the Age of the $4^{\text {th }}$ Industrial Revolution: the role of artificial intelligence, green bonds and cryptocurrencies. Technological Forecasting \& Social Change, 159, pp. 1-9.

Islam, T., Sheikh, Z., Hameed, Z., Khan, I.U., and Azam, R.I., 2018. Social Comparison, Materialism, and Compulsive Buying Based on Stimulus-Response Model: A Comparative Study Among Adolescents and Young Adults. Young Consumers, 19(1), pp. 19-37.

Jensen, M.C., 2002. Value maximization, stakeholder theory, and the corporate objective function. Business Ethics Quarterly, 12(2), pp. 235-256.

Kremer, C., Rizzuto, R. and Case, J.. 2000. Managing by the numbers: a commonsense guide to understanding and using your company's financials. New York: Basic Books.

Krishnannair, A., and Krishnannair, S., 2021. Learning environments in higher education: their adaptability to the $4^{\text {th }}$ industrial revolution and the "social transformation" discourse. South African Journal of Higher Education, 35(3), pp. 65-82.

Kuzmina, E.V., Pyankova, N.G., Tretyakova, N.V., and Botsoeva, A.V., 2020. Using data analysis methodology to foster professional competencies in business informaticians. European Journal of Contemporary Education, 9(1), pp. 54-66.

Lilien, G.L,. 2011. Bridging the academic-practitioner divide in marketing decision models. Journal of Marketing, 75(4), pp. 196-210.

Luoma, J., and Martela, F., 2021. A dual-processing view of three cognitive strategies in strategic decision making: intuition, analytic reasoning, and reframing. Long Range Planning, 54(3), pp. 1-15.

Madani, M., Vedadhir, A., Larijani, B., Khazaei, Z., and Gharamaleki, A.F., 2020. bridging the gap between ethical theory and practice in medicine: a constructivist grounded theory study. Science and Engineering Ethics, 26(4), pp. 2255-2275.

Mann R.P., 2018. Collective Decision Making by Rational Individuals. Proceedings of the National Academy of Sciences of the United States of America, 115(44), pp. E10387-E10396.

Marques, J.F., 2019. Flawed organizational purpose? changing the narrative in management education and practice. Development and Learning in Organizations, 33(5), pp. 24-26.

McCann, B.T., 2020. Using Bayesian updating to improve decisions under uncertainty. California Management Review, 63(1), pp. 26-40.

McLarney, W.J. and Berliner, W.M., 1974. Management practice and training: cases and principles, 6th ed. Holmwood, III: R.D. Irwin

Meek, C., Woodworth, W. and Dyer, W.G., 1988. managing by the numbers: absentee ownership and the decline of American industry. Reading, Mass: Addison-Wesley.

O’Brien, D.M., Kaluzny, A.D., and Sheps, C.G., 2014. the role of a public-private partnership: translating science to improve cancer care in the community. Journal of Healthcare Management, 59(1), pp. 17-29.

Parker, W.A.W., 2019. The divine proportions of Luca Pacioli. November 1. Kirkus Reviews.

Pratt, H.J., 199). Principles of effective performance management. Records Management Quarterly, 25(1), p. 28. 
Roberto, M. A., 2019. Unlocking creativity: how to solve any problem and make the best decisions. Hoboken, New Jersey: Wiley.

Sanchez, R. and Heene, A., 2010. Enhancing competences for competitive advantage. Bingley, UK: Emerald Group.

Schulz, S.A and Flanigan, R.L., 2016. Developing competitive advantage using the triple bottom line: a conceptual framework. Journal of Business \& Industrial Marketing, 31(4), pp. 449-458.

Senturk, i.F. and Coulibaly S., 2020. Mobile data collection in smart city applications: the impact of precedence-based route planning on data latency. Journal of Innovative Science and Engineering, 4(1), pp. 22-34.

Shepherd, D.A. and Gruber, M., 2021. The Lean Startup framework: closing the academic-practitioner divide. Entrepreneurship: Theory and Practice, 45(5), pp. 967-998.

Sternberg, R.J., Grigorenko, E., and Singer, J.L. (2004. Creativity: from potential to realization. Washington DC: American Psychological Association.

Tabuchi, H. and Gelles, D., 2019. Doomed Jets Lacked 2 Key Safety Features that Boeing Sold Only as Extras. New York Times, March 21.

Tolin, D.F,. 2014. Beating a dead dodo bird: looking at signal vs noise in cognitive-behavioral therapy for anxiety disorders. Clinical Psychology: Science and Practice, 21(4), pp. 351-362.

Vanka, P. and Sudha, T., 2017. Big data technologies: a case study. Research Journal of Science and Technology, 9(4), pp. 639-642.

Weinhardt, J.M., Hendijani, R., Harman, J.L., Steel, P., and Gonzalez, C., 201). How analytic reasoning style and global thinking relate to understanding stocks and flows. Journal of Operations Management, 39/40, pp. 23-30.

Witzel, M., 2012. A history of management thought. London, New York: Routledge. 